\title{
Study on the Mental Health Status of Pilots in Shanghai Port and the Intervention Countermeasures
}

\author{
Zhang Hanying ${ }^{1}$, Wu Changyue ${ }^{2, ~ *, ~ N i ~ Z h a n g f e n g ~}{ }^{3}$, Wang Deling ${ }^{2}$ \\ ${ }^{1}$ Shanghai Pilot Station, Shanghai, China \\ ${ }^{2}$ Merchant Marine College, Shanghai Maritime University, Shanghai, China \\ ${ }^{3}$ Shanghai Maritime Safety Administration, Shanghai, China \\ Email address: \\ keivnzhang1982@Sina.com (Zhang Hanying), Wu Changyue@shmtu.edu.cn (Wu Changyue), 77442070@qq.com (Ni Zhangfeng) \\ dlwang@shmtu.edu.cn (Wang Deling) \\ ${ }^{*}$ Corresponding author
}

\section{To cite this article:}

Zhang Hanying, Wu Changyue, Ni Zhangfeng, Wang Deling. Study on the Mental Health Status of Pilots in Shanghai Port and the Intervention Countermeasures. American Journal of Traffic and Transportation Engineering. Vol. 6, No. 4, 2021, pp. 128-132.

doi: 10.11648/j.ajtte.20210604.13

Received: July 10, 2021; Accepted: August 3, 2021; Published: August 7, 2021

\begin{abstract}
Shanghai is one of the busiest port in the world. With the continuous increase of traffic flow in Shanghai Port, the complexity of navigable environment and conditions is also increased, which undoubtedly increases the difficulty of ship navigation and directly affects the safety of ship pilotage. The mental health and good psychological quality of pilots are the important premise to ensure the safety of ship navigation. To ensure the safe navigation of ships in Shanghai port, it is very important to study the psychological state and pressure sources of pilots when they are engaged in the piloting work and put forward the measures to relieve the psychological pressure of pilots according to the actual situation. The paper focuses on explaining the current mental health status of pilots in Shanghai port, and analyzes the related factors that affect pilot's psychology, so as to find out the psychological pressure source of pilots and the influence of psychological factors on work performance. Through the analysis, combing with the current actual situation of Shanghai port, and understanding the current intervention measures at home and abroad, the author puts forward corresponding measures, according to the problems and factors that affect the psychological quality of pilots, and also hopes that the mental health status of pilots in Shanghai Port can be fundamentally improved, and lays a solid foundation for the safety of ship navigation.
\end{abstract}

Keywords: Pilots, Mental Health, Shanghai Port, Intervention Countermeasures, Psychological Pressure

\section{Introduction}

In recent years, the construction speed of Shanghai International Shipping Center has been advancing by leaps and bounds, which has also led to the development speed of ports along the Yangtze River basin. Under the influence of the above factors, the number of ships entering and departing from Shanghai Port has increased greatly. The original records of ships' pilotage number and tonnage have been broken over again by Shanghai Pilot Station, and this, to a large extent, also promoted Shanghai Port to obtain the title of the biggest container port in the world [1]. However, with the continuous increase of traffic flow in Shanghai Port, the complexity of navigable environment and conditions is also increased, which undoubtedly increases the difficulty of ship navigation and directly affects the safety of ship pilotage. The pilot's psychological status is an important factor that affects the navigation task. A good psychological status can ensure that the pilots can make good use of his own professional knowledge and skills to complete the navigation work. [2] Pilots need to work in accordance with the changeable hydrologic weather, as well as the actual navigation channel conditions, and in combination with the type and size of their own ships, to successfully complete the pilotage operations. The pilot's work is highly technical and has high risks, so the pilot's psychological quality is a very important accomplishment for this profession. This paper analyzes the status quo of ship traffic in Shanghai Port, and analyzes the sources and causes of the huge psychological pressure of 
Shanghai Port pilots by means of interviews, questionnaires and field survey, and put forward some suggestions to solve the psychological pressure of the pilots according to the actual situation,, which lays a foundation for the pilot to reduce the burden and ensure the safety of water traffic.

\section{Overview of Navigable Environment of Shanghai Port}

Shanghai port, which is a world famous port, is located in coast of East China Sea, the south bank of the Yangtze River estuary. The geographical location make Shanghai become the confluence point of the east-west transport channel of the Yangtze River and the north-south transport passage by sea. It is a major hub port along the coast of China. Since 2013, Shanghai Port has ranked first in container throughput and second in cargo throughput in the world, second only to Ningbo-Zhoushan Port.

Shanghai port is an important base of China's foreign trade and a national multi-functional hub port. It is the largest port along the coast of mainland China. It has established economic and trade relations with 221 countries and regions. Japan, the United States, and Germany are Shanghai's biggest trading partners, accounting for more than half of the city's total trade volume. Ninety nine percent of Shanghai's foreign trade supplies pass through Shanghai port, and its annual foreign trade throughput accounts for about 20 percent of the country's major coastal ports. As a world-renowned port, Shanghai Port's container throughput in 2020 reached 43.5 million TEU, ranking the first in the world for the 11th consecutive years [3].

There are several channels in Shanghai port including Nancao channel, Beicao Channel, Huangpu river, Yangshan channel and etc. And most of those channels are long and narrow with large traffic volume and complicated traffic flow. Thousands of ships pass through the channels every day. It brings great psychological pressure to the pilot's work. The ship traffic condition of Shanghai Port Channel is shown in Figure 1 below.

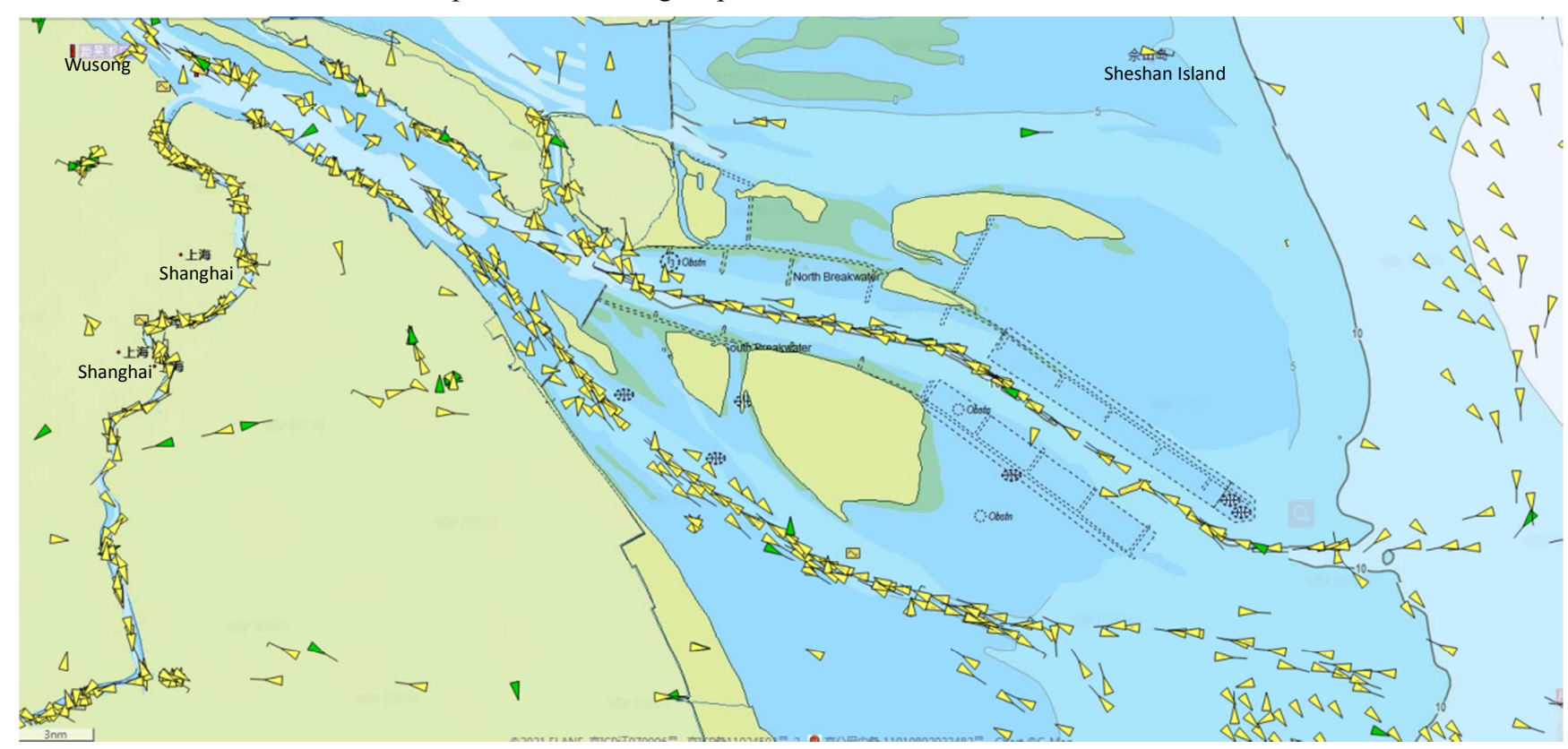

Figure 1. Vessel traffic condition in Shanghai port (time: 10:00LT 2021.7.10).

\section{The Psychological Qualities Required for the Job of a Pilot}

\subsection{Be Calm and Steady in Response to Emergencies}

As the pilots, their work is to assist ship's master to manoeuvre the ships in the harbour pilotage area safely. However, due to the limitation of the meteorological conditions and the conditions of the ship herself and the quality of the crew on the ship, it is impossible to ensure that each pilotage can be carried out smoothly, and there are often some unexpected situations or even dangers. When danger happens, how to deal with and dissolve the danger in the shortest time as a pilot has become the top priority. What is needed by a pilot at this time is a calm and stable mental state, which is the basic premise to ensure the smooth completion of the pilotage work. [4]

\subsection{Remain Confident in Taking Actions}

Being confident is very important for a pilot, and this psychological quality can affect the ship master and all related crew on the ship. Stable confidence allows relevant personnel, including the master, to follow the instructions of the pilot and carry out ship handling operations according to the requirements of the pilot. In addition, when confronted with emergencies and dangers, a stable and confident attitude can make the master fully trust the pilot, which to a large extent can relieve the nervous state of the crew in danger, so 
as to avoid chaos and successfully complete the pilotage work. [5]

\subsection{Have Good Psychological Endurance and Proficiency in Pilotage Skill}

Good psychological endurance and proficiency in pilotage skill are the basic requirements of pilot's psychological accomplishment. As the Chinese saying goes, "Boldness of execution stems from superb skill". What is emphasized here is that, on the one hand, superb pilotage skills are the basis of good psychological endurance, and on the other hand, good psychological endurance is the premise of pilotage skill. In a word, a qualified pilot need both good psychological endurance and proficiency in pilotage skill. [6]

\section{The Importance of Pilot's Psychological Quality}

The pilot's psychological status is an important factor that affects the navigation task. A good psychological status can ensure that the pilots can make good use of his own professional knowledge and skills to complete the navigation work. Pilots need to work in accordance with the changeable hydrologic weather, as well as the actual navigation channel conditions, and in combination with the type and size of their own ships, to successfully complete the port operations. The pilot's work is highly technical and has high risks, so the pilot's psychological quality is a very important accomplishment for this profession [7]. During the process of actual work, the pilot's life routine (word and rest) and their family's atmosphere are the reasons that can affect the pilot's psychological status, and the pilots often suffers from various pressures such as life and work. Therefore, there are extremely high requirements for the psychological quality of pilots, which not only requires pilots to have flexible adaptability, but also needs to play the perfect operation skills in practical work, so as to ensure the safe driving of ships and the safety of navigation of ships [8].

The navigation environment of Shanghai port is very complex, so the pilot's work and rest in Shanghai port can not be guaranteed fully, their work and rest will be changed by irregular semi-diurnal tide irregularly. Due to this, the pilot's work in Shanghai port is very hard, which causes certain psychological pressure for pilots. The mental health of pilots to a certain extent affects the safe driving of ships, and due to the psychological problems of pilots, there are many navigation accidents [9]. Therefore, in order to ensure the safety of ship navigation, it is necessary to make an in-depth analysis of the current psychological status of pilots in Shanghai port, and analyze the related factors that will affect the psychological status of pilots, and fundamentally alleviate the psychological pressure of pilots in Shanghai port and relieve their bad emotions, which has practical significance for ensuring the safety of ship navigation.

\section{Source of Pressure Affecting the Mental Health of Pilots}

The mental health of pilots in Shanghai port is mainly influenced by all kinds of stress, that is, the sources of pressure. The sources of pressure, also known as stressor or tension source, it is also a challenge to individual adaptability, it is a source in order to promote individual to produce the response for stress. The source of pressure can be classified according to different categories and different ways. And the source of work pressure mainly refers to the response that the individual has much pressure under the working environment [10].

\subsection{Sources of Pressure of Pilots Who Works at Shanghai Port}

In order to understand the source of pressure of pilots who works at Shanghai port, the author has a deep understanding through questionnaires, conversations and other ways. After summarizing and analyzing the survey results, we can find that the source of pressure of pilots in Shanghai port mainly can be divided into five aspects:

1) The pressure caused by work load. The work load is mainly caused by the great volume and difficulties of work, and the pilot's poor experience about their work;

2) The pressure caused by the nature of the work. The pilot's work has its special nature of high risk, and there are many unexpected situations in the process of their working;

3) The pressure caused by personal career development, which is directly related to the pilot's narrow career development scope;

4) The pressure caused by organizational structure and atmosphere, which is related to the lack of effective communication between the pilot and his colleagues, or the pressure that is gradually generated as a result of the difficulty in adapting to the strict management system; [11]

5) The pressure caused by the pilot's family conflicts. For example, due to the irregular working hours, the pilots can't accompany his family as normal families, and other factors such as disproportionate contributions and his salary will also bring pressures to the pilots.

\subsection{Reaction of Pilot Under Working Pressure in Shanghai Port}

Based on the investigation and research of pilots in Shanghai port, it is found that the pilots usually have three main manifestations when facing the work pressure:

1) Anxiety

Many factors in pilots' work will cause pilot's anxiety. Pilots will have some anxieties when they are waiting for the tasks and when they know that the pilotage plan has been changed, and when they are facing these uncontrollable risks and factors such as the sudden climatic factors; [12]

2) Fatigue

Fatigue is the main pressure reaction of pilots in their work. There are many factors that lead to fatigue, for example, the 
irregular working will directly affect the pilot's rest. Inadequate rest will directly lead to fatigue, the greater work intensity will also lead to fatigue, and the pilot's own life pressure will also lead to fatigue; [12]

3) Fear

There are many factors that cause pilots to have fear psychology. When they climb the pilot ladder, someone will fear for his personal safety, and in the course of pilot's navigation, someone will fear to a certain extent because of the harsh navigation environment, sudden promotion of professional title, the aggravation of responsibilities, and worries about the occurrence of accidents.

\section{Psychological Intervention Measures}

According to the actual reaction status of pilot's pressure and the working pressure source in Shanghai port, the corresponding intervention measures should be put forward in view of the existing problems. Based on this, the author consults a large number of research literatures at home and abroad, and studies the related theories, and the author thinks that corresponding psychological intervention measures for pilot in Shanghai port can be conducted from the three aspects of management, individual and society, so as to fundamentally establish psychological pressure intervention for pilots.

\subsection{Intervention at the Management-Level}

A relatively relaxed navigation environment for pilots should be created, and in the process of their actual work. Pilots should actively participate in the construction and design of berths according to their own professional expertise, so that pilots can have a clearer understanding of the hydrology of ports and docks [13]. What's more, in the process of pilot's work, during the preliminary examination period of wharf construction, the pilot can put forward some factors that may affect the safety of navigation, so as to better urge the port and wharf managers to do the preparatory work related to berthing in order to ensure that the pilot can operate the follow-up work successfully. On the other hand, the evaluation of occupational psychology should be strengthened, which should be paid enough attention in navigation personnel management. Navigation is a high-risk job, which often faces life-threatening and various safety accidents, and also needs to undergo chaotic diet rules. Therefore, the selection of professional psychology should be regarded as the key point in the selection of pilots. It is also necessary to be regarded as an important measure for pilots. And so, the professional adaptability of pilot workers can be also strengthened, so as to fundamentally improve the efficiency of pilot activities, and strengthen the effectiveness of pilot vocational training activities, and minimize the waste of resources, and fundamentally ensure the safety of navigation operations.

\subsection{Intervention at the Individual Level}

First of all, the training of pilots' professional skills should be strengthened. Focus on the training of pilots' professional skills, Navigation institutions can cooperate with relevant maritime colleges and universities to establish practical training of navigation simulators and corresponding life-saving bases, which can provide regular simulation training and the corresponding emergency response training for pilots. By carrying out practical professional training, the pilot's psychological bearing capacity can be greatly improved, which can stimulate the pilot to have a clear and correct judgment and have the ability to save life when encountering corresponding difficulties in actual working, so that he can calmly face various unexpected situations and ensure the safety of ship navigation. [14] And then, it is necessary to strengthen the sense of responsibility of pilots in their work, observe the rules and regulations in the daily life, and clearly know the importance of pilot safety to the country, society and individuals, and fundamentally strengthen the safety awareness of pilots and improve their professional quality. What's more, the pilots should control their personal emotional management, and they should have perception, control and adjustment of their own emotions. It is not a good way to suppress someone's emotions, so pilots should try their best to find ways to relieve and alleviate their bad emotions and pressure, find the suitable ways to release their bad emotions, and control the personal emotional reasonable.

\subsection{Intervention at the Social Level}

People's behaviors are often influenced by their colleagues or friends around them. When pilots are at a loss about their problems, they often find answers from others. Therefore, under such circumstances, the pilot's colleagues, friends and family members need to communicate well with the pilots, and give comfort and understanding for pilot, and take practical actions to help the pilot overcome his psychological pressure [15]. In addition, the pilot organization should give full play to the strengths of industry organizations, and strengthen the training of pilots on mental health and practical ability. For example, the pilot organization can organize some pilots to study on ocean-going ships regularly, and the pilots can learn the operation skills of ships in this process, and understand and master the various driving experiences and new navigation equipment. The pilot organization also can organize the pilot to study at all kinds of large ports at home and abroad, the pilots can absorb the advanced concepts in the learning process. In the process of pilot's actual work, the "master-apprentice system" can also be applied, so that the experienced pilots can lead and teach the young pilots about work, and in the process, young pilots can accumulate experience continuously.

\section{Conclusions and Recommendations}

In a conclusion, the psychological quality of pilot in Shanghai port is uneven. Therefore, there is still much room for improvement about the pilot's mental health level. The psychological intervention for pilots can be carried out from 
three aspects: management, individual and society, there should be a platform that pilots can understand and master professional knowledge and work skills as much as possible, and fundamentally reduce the psychological pressure of pilots, it is a great practical significance for ensuring the safety of navigation.

The traffic environment is changing with the development of the port, and the psychological pressure of the pilot is also changing, so is the port of Shanghai. Therefore, study on pilot mental health is a process of continuous improvement. As personnel engaged in pilotage work and research, the authors of this paper will continue to track and study various aspects of mental health of pilots according to the change of working environment of pilots in Shanghai port, in order to better solve the psychological problems of pilots, and ensure the safety of pilotage operation.

\section{References}

[1] Zhou Bin. Research on Risks of Ship Pilotage Manipulation in Shanghai Port [J]. Pearl River Water Transport, 2020 (19): $9-10$.

[2] Hu Zhongming. Psychological stress and thinking of pilots under the background of public health emergencies [J]. China Water Transport, 2021 (07): 122-124.

[3] http://www.ce.cn/cysc/newmain/yc/jsxw/202102/01/t2021020 1_36279817.shtml.

[4] Zhu Xiaomin. Discussion on the Cultivation of Pilot's Psychological Quality [J]. China Water Transport, 2012, 12 (02): 44-45.

[5] Li Tao, Bao Fengjun, Xu Yanan. Study on occupational pressure of pilots in Yangtze River Delta seaport based on factor analysis [J]. Navigation, 2021 (01): 51-54.

[6] Tang Hongping. Discussion on the management of pilot group psychology [J]. Pearl River Water Transport, 2021 (08): 88-89.

[7] Yang Rong, Bai Xiangen, Ling Guiyang. Analysis on the Mental Health Status of Pilots in Shanghai port and Intervention Countermeasures [C]// China institute of navigation. China institute of navigation, 2015.

[8] Xie Ming. (2012). Study on Mental Health Characteristics and Influencing Factors among International Seaman in Shanghai port. (Doctoral dissertation, Fudan University).

[9] Zhang Bingcheng. The Pilot's Responsibility for the Safe Operation [J]. Navigational Technology, 2005 (4): 19-21.

[10] Zhang Jinpeng, Chen Weijiong, Zhang Hao, \& Zhan Haidong. (2013). Research on Ship Pilot Reliability Evaluation System. China Safety Science Journal (05), 76-81.

[11] Li Zhanyong. Occupational Psychological Characteristics of Pilots and Management Suggestions [J]. China Water Transport, 2021 (04): 126-128.

[12] Du Weijie, Xiao Shuwu, Niingbo Pilot. Research on the Safety Protection Measures of Pilot Ship Transports the Pilots [J]. 2011 Academic Symposium of Jiangsu, Zhejiang, Fujian and Shanghai Navigation Society, 2012.

[13] Li Tongiiao. Preliminary Study on Pilot Career Planning and Management in China. (Doctoral dissertation, Dalian Maritime University).

[14] Xia Yunfeng. Study on Pilot competency [J]. China Water Transport, 2020 (06): 35-36.

[15] Bao Fengjun. Discussion on the Training and Promotion of the Technical and Psychological Quality of Pilots in China [C]// 2010 . 